\title{
A ESPERANÇA INDÍGENA ATRAVÉS DE POLÍTICAS PÚBLICAS BRASILEIRAS
}

\author{
INDIGENOUS HOPE THROUGH BRAZILIAN PUBLIC POLICIES
}

\section{LA ESPERANZA INDÍGENA POR MEDIO DE POLÍTICAS PÚBLICAS BRASILEÑAS}

\author{
Marcio Magera Conceição', Ricardo Shitsuka², Maria Fani Scheibel ${ }^{3}$, Max Leandro de Araújo Brito4
}

\section{RESUMO}

Estima-se que os povos indígenas no Brasil contavam com uma população em torno de 2 a 5 milhões de habitantes na época do descobrimento. Atualmente há cerca de um milhão. Muitas vezes há desânimo diante da falta de perspectivas nesses povos, muitos dos quais vivem em regiões afastadas nas matas. O objetivo do artigo é desvelar as representações sociais associadas às perspectivas desses povos e a sua possibilidade de melhoria. Realiza-se uma pesquisa na qual se verifica as representações sociais por meio de entrevista, no ano de 2017, em graduandos de um curso de Licenciatura Indígena. Verificou-se nos entrevistados, a presença do senso comum que aponta para a necessidade da educação dos povos indígenas. Observou-se a esperança para melhoria das condições desses povos que vem através dos cursos de Licenciatura Indígena que têm ajudado a preservar aspectos histórico-sociais, culturais e possibilidades futuras uma vez que os licenciados voltam para suas aldeias para trabalhar a educação básica nos jovens.

PALAVRAS-CHAVE: Educação. Ensino. Licenciatura intercultural. Formação Indígena. Confiança.

\footnotetext{
1 Pós Doutorando junto a Faculdade Funcional de Ecologia Universidade de Coimbra, Portugal. Projeto em andamento, ano 2018.Pós Doutor junto ao Departamento de Sociologia do Instituto de Filosofia e Ciências Humanas IFCH da Unicamp, SP, sob orientação do Prof. Dr. Ricardo Luiz C. Antunes. Ano 2004 e 2005.Post Doctor in International Relations, do Programa de Estudos de Pós-graduação stricto sensu da Florida Christian University FCU. Memorial de conclusão de curso entregue em novembro de 2013, no Seminário Internacional em Orlando Florida, USA, 2013.Doutor em Ciências Sociais Sociologia Na Pontifícia Universidade Católica de São Paulo-Puc, SP. 2002.Doutor em Administração de Negócios na Florida Cristhian Universit FCU USA, 2010.Mestre em Ciências Sociais Área de Concentração Sociologia, pela Puc SP, 2001. Mestre em Administração de Empresas pela Universidade de Guarulhos -SP, 1999.MBA de Gestão de Marketing na ESAMC Sorocaba, SP, 2007Graduado: Bacharel em Ciências Econômicas - Pontifícia Universidade Católica de Campinas SP. Ano 1993.Jornalista MTB 556.03.81V-SP. Correio eletrônico: magera1963@gmail.com

2 Doutor em Enino de Ciências na Universidade Cruzeiro do Sul. Mestre em Engenharia pela EPUSP.Pós-graduação em Tecnologia, Formação de Professores e Sociedade na UNIFEI.Pós-graduação em Tecnologias Educacionais pela FAAP. Pós-graduação em Design Instrucional para EAD pela UNIFEI. Graduação em Pedagogia. Graduação em Odontologia. Graduação em Licenciatura em Computação Graduação em Engenharia. Correio eletrônico: ricardoshitsuka@unifei.edu.br
}

3 Doutorado em Ciências da Educação pela Universidade Pontifícia de Salamanca, Espanha. Pós-doutorado pela UNICAMP. Atuou na FURG. É avaliadora do INEP. Atua em EaD. É Professora do Instituto Paranaense de Pesquisa e Ensino em Odontologia . Correio eletrônico: mfani@terra.com.br

4 Prof. Dr. Max Leandro de Araújo Brito, resumidamente, é prof. Professor Adjunto na Universidade Federal do Rio Grande do Norte - UFRN Possui graduação em Biologia pelo Claretiano Centro Universitário; Administração pela Universidade Federal do Rio Grande do Norte. Especialização em Educação a Distância pela Faculdade de Tecnologia e Ciências; mestrado em Administração Universidade Federal do Rio Grande do Norte; doutorado em Energia pela Universidade Federal do ABC e pós-doutorado pela Universidade Federal do ABC. Correio eletrônico: maxlabrito@gmail.com 


\begin{abstract}
It is estimated that indigenous peoples in Brazil had a population of about 2 to 5 million inhabitants at the time of discovery. There are now about one million. There is discouragement and in face of lack of perspective on these peoples, many of whom live in remote regions of the forest. The purpose of this article is to unveil the social representations associated with the perspectives of these peoples and their possibility of improvement. A research is carried out in which the social representations are verified by means of interviews, in the year of 2017, in undergraduates of an Indigenous Licentiate course. It is verified among the interviewees, the common sense that points to the need of education of indigenous peoples. It was observed the hope for the improvement of the conditions of these peoples that come through the courses of Indigenous teachers formation that have helped to preserve historical-social aspects, cultural and future possibilities once graduates return to their villages to work on basic education of young people.
\end{abstract}

KEYWORDS: Education. Teaching. Intercultural bachelor. Indigenous formation. Confidence.

\title{
RESUMEN
}

Se estima que los pueblos indígenas en Brasil contaban con una población de alrededor de 2 a 5 millones de habitantes en la época del descubrimiento. Actualmente hay cerca de un millón. Hay el desánimo diante de la falta de perspectivas en esos pueblos muchos de los cuales viven en regiones alejadas en los bosques. El objetivo del presente artículo es desvelar las representaciones sociales asociadas a las perspectivas de esos pueblos y su posibilidad de mejora. Se realiza una investigación en la que se verifican las representaciones sociales por medio de entrevista, en el año de 2017, en graduandos de un curso de Licenciatura Indígena. Se observó en los entrevistados el sentido común que apunta a la necesidad de la educación de los pueblos indígenas. Se trató de una esperanza para mejorar las condiciones de esos pueblos que vienen a través de los cursos de Licenciatura Indígena que han ayudado a preservar aspectos histórico-sociales, culturales y posibilidades futuras una vez que los licenciados regresan a sus aldeas para trabajar la educación básica en los jóvenes.

PALABRAS CLAVE: Educación. Enseñanza. Licenciatura intercultural. Formación indígena. Confianza.

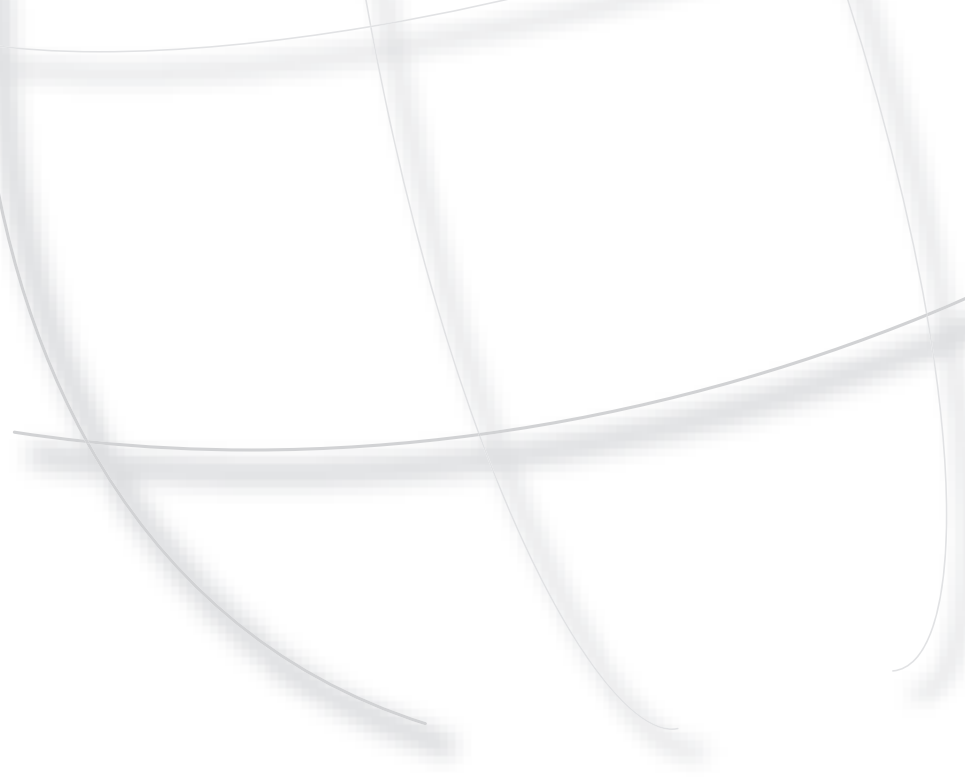




\section{INTRODUÇÃO}

O Brasil é um país de dimensões muito grandes com seus mais de 8 milhões e 500 mil quilômetros quadrados. Neste país há riquezas minerais no solo que ainda não foram exploradas, e há grandes áreas de terra que podem interessar o agronegócio que precisa de áreas de plantio e para criação de gado e outros animais, muitas vezes em regiões interioranas habitadas por muitos povos indígenas.

Atualmente, os agronegócios representam cerca de um terço da riqueza produzida na economia brasileira e a produção de alimentos é importante tanto para o mercado nacional quanto para o mundial. Brasil (2017) considera que a tecnologia tem sido um dos principais fatores que contribuem para incentivar o desenvolvimento e crescimento da agricultura brasileira. Para que ocorra uma produção de grãos que atenda a demanda atual mundial e nacional dos próximos anos de 2017 a 2027 , é preciso que haja um aumento anual de $1,5 \%$ de modo a passar dos atuais cerca de 60,4 milhões de toneladas para o valor de cerca de 71 milhões em 2027. Há desafios que precisam ser superados para que se possa alimentar o mundo e o país.

Observa-se que além da tecnologia, serão necessárias mais áreas de terra. A complexidade se estabelece uma vez que o mundo precisa de mais alimentos e paga por isso, por outro lado, a produtividade tem sido trabaIhada e tem crescido de modo a se ter mais produção no mesmo espaço de terra, no entanto as necessidades de alimentos estão aumentando e há a demanda por mais terras, sendo que muitas destas já estão ocupadas.

No ano de 1500 existiam muitas florestas no solo brasileiro e já havia habitantes que eram os povos indígenas. Para Azevedo (2008) havia cerca de 2 a 5 milhões de habitantes na época do descobrimento e a população diminui ao longo dos séculos até chegar aos dias atuais. Nos anos mais recentes, o IBGE (2010) enxerga mais de 240 povos indígenas que somam 896.917 pessoas. Desses, 324.834 vivem em cidades e 572.083 na região interior. Observa-se uma diminuição da população indígena ao longo dos séculos e mesmo atualmente há o desânimo e a falta de perspectivas. Há também a extinção de várias línguas indígenas. Como apresenta Folha (2018) existem mais que 190 línguas indígenas com risco de extinção.

O objetivo do artigo é desvelar as representações sociais associadas às perspectivas desses povos e a sua possibilidade de melhoria em estudantes de povos indígenas. Nas linhas seguintes apresentam-se o item relacionado à queda da quantidade de indígenas no Brasil desde a época do descobrimento aos dias atuais, procurando discutir as causas à luz da literatura.

\section{CAUSAS DA DIMINUIÇÃO NA QUANTIDADE DE INDÍGENAS NO BRASIL}

Moonen (2008) considera um número diferente dos anteriormente mencionados, mas dentro da faixa do IBGE (2010). Para o autor (Ibid) em 1500 havia cerca de 4 milhões de indígenas. Daquela época aos dias atuais houve processos que fizeram com que a população indígena caísse para cerca de um milhão. Alguns fatores para a diminuição da população indígena brasileira (lbid) foram: escravidão indígena do início do período colonial, guerras entre povos indígenas, doenças trazidas pelos colonizadores que eram desconhecidas dos indígenas como é o caso da gripe, sarampo, tuberculose e varíola. Grande parte dos povos indígenas mora em aldeias distantes dos centros urbanos no meio da mata e, não têm acesso à informação.

Nos anos mais recentes, segundo o Cimi (2015) cresceu a violência contra os indígenas em 2015: houve a extração ilegal por madeireiros de madeira em terras indígenas, aconteceram mortes por pneumonia, diarreia e gastroenterite. Essas são doenças que são facilmente tratáveis nos tempos atuais. Por outro lado, fazendeiros criaram milícias permitindo a ocorrência de assassinatos, espancamentos, sequestros, torturas e estupros contra indígenas, procurando se apossar das terras que pertenciam a esses povos.

Segundo Barreto (2016) há uma prática de infanticídio em povos indígenas no Brasil. Acrescente-se a este fato, as más condições de higiene e a desnutrição que levam à mortalidade infantil. De fato, há fatores que são nocivos à sobrevivência dos indígenas e entre outros há também a bebida, prostituição e violência contra os indígenas e que fazem com que sejam segregados contra a Lei brasileira. Brasil (1997) na Lei n. 9.459/1997 prevê penas de reclusão e multas para várias situações de discriminação de cor, raça e etnia. Infelizmente, nem sempre a lei é respeitada e cumprida por diversos motivos presentes na cultura brasileira e entre os quais está a falta de educação. 
Morgado (1991) ao estudar uma epidemia de suicídio entre os indígenas Guarani-Kaiowa, considera que há vários casos de suicídio indígena no Mundo assim como há casos de inclusão condigna que deram certo. Oliveira e Lotufo Neto (2003) ao estudarem a tribo Caiowa encontram taxas de suicídio 40 vezes maiores que a média nacional. As taxas de suicídio são relativamente elevadas. Souza e Orellana (2013) ao estudarem as relações de suicídio de jovens no Estado do Amazonas, concluíram que para a mesma faixa etária, o suicídio de indígenas era 4,4 vezes maior que o dos não-indígenas. Dessa forma, a quantidade continua sendo maior entre os indígenas.

Pereira (2017) estuda o suicídio indígena entre jovens em São Gabriel da Cachoeira no Amazonas, município cuja população autodeclarada indígena excede $70 \%$ da população total e, conclui que os principais fatores identificados foram: desemprego, conflitos familiares, dificuldades nos relacionamentos e consumo elevado de álcool e drogas e terem sido vítimas de "sopro" (feitiço xamânico), o que levou os suicidas ao envenenamento ou enforcamento. No estudo, a autora fez uso de levantamentos por meio de representações sociais obtidas por meio de entrevistas em grupos focais de indígenas.

Há a falta de perspectiva muito grande que é coerente com os tempos nos quais vivemos, trazidas pelo pós-modernismo Lyotard (1979) define um limite entre modernidade na qual as pessoas tinham confiança, empregos duradouros e segurança em relação aos tempos pós-modernos nos quais há individualismo, falta de valores e desesperança. Para Hanke (2015), na pós-modernidade, as mudanças estruturais da contemporaneidade baseiam-se na digitalização de informação e abrem possibilidades para as mudanças sociais. Uma das possibilidades que consideramos é a chegada da informação para mais perto dos povos indígenas, porém sem saber até que ponto os efeitos podem ser positivos ou não. Já Bauman (2007) vê a pós-modernidade superada e considera que vivemos em tempos líquidos onde nada é feito para durar e a exclusão e desintegração da solidariedade trazem mais medo e descrença para as pessoas. Verifica-se que há muitas causas que em conjunto favorecem a ocorrência do suicídio principalmente entre os jovens indígenas

\section{AS REPRESENTAÇÕES SOCIAIS E O SENSO COMUM}

Moscovici (2009) considera que representar envolve categorizar e classificar algo. Na realidade se juntamos um conjunto de comportamentos e regras que estipulam o que é, ou não é possível, em relação aos membros da categoria vamos formando pensamentos comuns. Estes se tornam importantes nas comunicações, uma vez que as pessoas precisam ter o senso comum para poder se comunicar e se entender.

Jodalet (1985) conceitua as representações sociais como sendo modalidades de conhecimento prático orientadas para a comunicação e compreensão do contexto social, material e ideativo em que vivemos e se manifestam por meio de imagens, conceitos, categorias e teorias. Desta forma, consideramos como sendo as representações do senso comum. Silva, Shitsuka e Shitsuka (2015) num estudo sobre a imprensa brasileira, concluem que as representações sociais mostram como as opiniões são orientadas por crenças sociais e, a partir das análises, concluem que as mídias refletem e refratam as representações sociais.

A reflexão é o espelhamento do que existe e a refração é a mudança de direção mantendo características importantes. Braga e Campos realizaram um estudo semelhante relacionado a povos indígenas, procurando verificar as representações a respeito da identidade dos indígenas, porém em mídia impressa ou seja, em jornais. Os autores concluíram em seu estudo que:

As representações sociais dos indígenas veiculadas pela mídia são, na verdade, parte de um processo de manutenção do statu quo de determinados atores sociais. Essa construção, que também é social, intenciona manter um discurso hegemônico de uma democracia racial à brasileira, toda ela construída à custa da marginalização de grupos (negros, indígenas etc.) minoritários em favor dos grupos majoritários (BRAGA; CAMPOS, 2013).

Observa-se que os autores constataram que há algo semelhante a uma "ditadura das maiorias" e este é um fato para reflexão no sentido de se buscar alternativas que sejam boas para todos os envolvidos ou se bus- 
car soluções para condições complexas e essas exigem pessoas mais bem preparadas, capazes de estudar e considerar várias variáveis.

Os povos indígenas são minoria e geralmente não recebem um pagamento pelas suas terras que the são tomadas por desconhecimento das formas de ação junto à sociedade e de modo a encontrar agendas positivas junto a sociedade de modo a procurar pontos de convergência que leve ao máximo o bem de todos. Os trabalhos complexos, muitas vezes são semelhantes a um grande tabuleiro e jogo enxadrístico como considera Shitsuka et al. (2004). Neste os bons players conseguem enxergar muitas jogadas à frente de todo o tabuleiro e não somente alguma região que pode levar a um pequeno lucro temporário, mas, a uma perda futura maior ou até mesmo irrecuperável.

Um dos aspectos interessantes das políticas públicas brasileiras para os povos indígenas foi a criação de cursos de Licenciatura Indígena os quais são voltados para alunos indígenas os quais após formados serão professores atuantes nas aldeias de onde vieram. Alguns princípios legais desses cursos são:

Art. $2^{\circ}$ Constituem-se princípios da formação de professores indígenas:

I - respeito à organização sociopolítica e territorial dos povos e comunidades indígenas;

II - valorização das línguas indígenas entendidas como expressão, comunicação e análise da experiência sociocomunitária;

III - reconhecimento do valor e da efetividade pedagógica dos processos próprios e diferenciados de ensino e aprendizagem dos povos e comunidades indígenas;

IV - promoção de diálogos interculturais entre diferentes conhecimentos, valores, saberes e experiências;

V - articulação dos diversos espaços formativos, tais como a comunidade, o

movimento indígena, a família e a escola; e, VI - articulação entre docentes, gestores e demais profissionais da educação escolar e destes com os educadores tradicionais da comunidade indígena (BRASIL, 2015).

Por meio do Decreto de 2015, acreditamos que os cursos de Licenciatura Indígena foram balizados e, neles procura-se trabalhar com respeito ao futuro professor indígena procurando trabalhar além do idioma português, as línguas de cada povo e, buscando preservar a identidade com o desenvolvimento do registro da tradição oral dos povos, suas danças, tradições e cultura. Estas sendo respeitadas e valorizadas fazem com que o aluno passe a ter mais confiança na sociedade e nas possibilidades de trabalho com seu povo, outros povos e o diálogo com a sociedade.

Segundo Brasil (2016) os cursos de Licenciatura Indígena estão trabalhando para fortalecer a cultura e língua indígenas de modo a tentar respeitá-las e preservá-las. À medida que os povos indígenas percebem este caminho pelo saber, eles têm enviado representantes para os processos seletivos das universidades e desta forma, há a participação dos alunos que futuramente vão atuar nas suas respectivas aldeias.

\section{METODOLOGIA}

Uma pesquisa é estudar algum assunto ou fenômeno e com o objetivo de obter novos conhecimentos. Para Gil (2017) a pesquisa é um procedimento sistemático que é importante e necessário para alcançar as respostas aos problemas. Nas pesquisas torna-se importante o emprego de metodologias que indiquem os caminhos a serem seguidos para realizar as pesquisas. São necessários os instrumentos e técnicas para se realizar os levantamentos para obter os dados e depois faz-se o estudo e interpretação deles. Uma pesquisa qualitativa se foca no aspecto subjetivo do objeto estudado e torna-se importante a intepretação que se dá ao fenômeno que está sendo estudado e, como consideram Pereira et al. (2018) e também Ludke e Andre (2013), ela ocorre em ambiente natural em um contexto social em alguma esfera de comunicação.

Bakhtin (2011), quando estuda a estética da comunicação, pondera que existem várias esferas de comunicação e cada uma conta com seus gêneros textuais. Esses são componentes importantes dos processos comunicacionais. Na esfera da academia, há os gêneros das teses, dissertações, monografias, livros, artigos e produções diversas. Na comunicação oral ou escrita dos grupos pode-se captar as representações sociais existentes e isso pode ocorrer também nas redes sociais. Para Mattar (2017) o uso dos recursos computacionais e 
da grande rede mundial na realização das pesquisas as beneficia uma vez que são as ferramentas dos tempos atuais que nem todos pesquisadores ainda fazem uso.

Realiza-se também a análise de conteúdo seguindo a linha francesa. Pechêux (2007) considera que para o entendimento do conteúdo torna-se necessária a busca de informações em elementos externos relacionados à fenomenologia. Apresenta-se no item seguinte, os resultados e discussões.

Por questões de respeito ao pedido dos participantes e de questões éticas evitou-se citar os nomes dos envolvidos e localidades.

\section{RESULTADOS E DISCUSSÕES}

Durante uma visita a um curso de Licenciatura Indígena realizado no ano de 2017, realizou-se a entrevista de alunos de um curso de Licenciatura Indígena brasileiro. Como os alunos do curso moram em aldeias no interior da mata nativa, muitas vezes demoram dias para chegar à universidade. Havia casos de estudantes que demoravam cerca de 10 dias saindo da aldeia, andando pela mata, pegando canoas, outros barcos e mais caminhada até chegar ao campus universitário para estudar.

Em virtude das dificuldades na época, houve uma entrevista com 6 alunos que são transcritas como amostras. Incialmente se apresenta algumas imagens emprestadas da Web por irem claramente ao encontro do tema proposto. Brasil (2016) afirma que existem 16 cursos superiores desta licenciatura no território nacional. Os cursos valorizam a cultura e língua de cada etnia o que torna complexo o trabalho dos professores e o próprio entendimento dos colegas de curso e por este motivo são considerados como sendo interculturais.

Para Morin (2014) para lidar com a complexidade torna-se interessante o respeito às diferenças, a busca do amor ao próximo e o emprego de estratégias que incluem utilizar o que estudantes já conhecem das suas aldeias, suas danças, histórias, artesanato, uso de ervas medicinais etc. Os saberes dos alunos são empregados nos diversos projetos ao longo do curso de modo que eles adquirem o gosto pela pesquisa e busca do saber e aprendem a aprender.

Verificou-se que os alunos do curso, ao retornar as suas aldeias respectivas, realizam o trabalho educacional junto a sua etnia utilizando saber específico e direcionado em relação a danças, artes, cantos, tradições etc que são próprios da etnia à qual pertence um aluno específico e este fato permite que ocorra uma maior aderência e aceitação por parte da respectiva comunidade indígena e possibilita o fortalecimento da cultura, da identidade e, por conseguinte, previne a ocorrência do suicídio.

Para Botega (2014) que estudou o suicídio em indígenas, estes são causados por fenômenos psicossociais complexos. Desta forma, a própria prevenção também se torna difícil e o fortalecimento da cultura é uma maneira de diminuir esse fenômeno. Os diálogos com os alunos mostraram que há confiança deles e dos seus povos na educação fornecida pela universidade e o senso comum é que vale a pena o esforço e dedicação ao aprendizado pelo aluno.

AAmostra 1 é de uma declaração de aluna de um curso de Licenciatura Indígena da região Sul do Brasil.

Amostra 1: Essas graduações que estão abrindo nas universidades voltadas para os povos indígenas são importantes porque é dessa maneira que nós vamos conseguir continuar mantendo nossa língua, cultura e costumes tradicionais.

Fonte: Brasil (2016)

Análise: A declaração da aluna vai ao encontro da legislação para os cursos de Licenciatura Indígena como considera Brasil (2015). Tudo leva crer que os cursos estão atendendo às expectativas dos povos indígenas e que há uma procura crescente de membros das tribos por esse tipo de curso superior. $O$ trabalho nesses cursos muitas vezes se mostra complexo uma vez que o aluno que vem de aldeias distantes e do interior da mata com dificuldades em chegar ao campus universitário podendo gastar dias para alcançar seu destino entre a aldeia e o campus.

Outro aspecto complexo é o trabalho com línguas diferentes. Cada povo pode ter sua língua própria e como considera Folha (2018) há muitos idiomas que estão em risco de extinção. Torna-se interessante o trabalho dos professores de modo diferenciado com os alunos, procurando preservar o idioma e cultura de cada um e buscando trabalhar a cidadania e respeito entre as diferentes etnias dos povos indígenas.

Verifica-se que há um senso comum entre os alunos de cursos de Licenciatura Indígena no sentido de 
que esses cursos têm ajudado a preservar a cultura e a língua dos seus povos trazendo esperança e, por conseguinte, conseguem apoiar de alguma forma na prevenção do suicídio indígena.

Realizou-se a entrevista de alguns estudantes do curso de Licenciatura Indígena da UFAC durante uma visita realizada no campus Floresta e, eles trouxeram as seguintes colocações em relação ao curso.

Amostra 2: No curso tem colegas de outras aldeias. Nossas línguas são diferentes e um aprende com o outro. Nós não tínhamos contato e hoje somos colegas de turma e amigos. Aprendemos o português e graças aos professores e colegas.

Análise: É muito importante considerar os laços de amizade formados, a interação que ocorreu quebrando barreiras e favorecendo o entendimento entre os povos que conservaram seus idiomas e, além disso, aprenderam um novo que é o português, ampliando seu saber sem deixar de lado o saber dos respectivos povos que é trabalhado pelos professores formados em suas aldeias.

Por meio da interação entre indígenas de povos diferentes observou-se que passa a existir um sentido de cooperação e por meio deste trabalho é possível que haja menos conflitos entre as diferentes etnias e povos que passem a se respeitar e buscar um trabalho colaborativo entre os povos de modo minimizar a quantidade de mortes por guerras entre diferentes povos.

Como considera UN (2008) é preciso ter respeito pelas línguas e culturas e era necessário aprender um idioma comum que não invalidaria os já possuídos pelos estudantes, mas que ajudaria a melhorar a comunicação. Foram muitos os obstáculos que os alunos passaram para frequentar o curso como o deslocamento até a universidade.

Quando os alunos passam a conhecer seus colegas e verificar que todos têm problemas comuns e, podem se ajudar, deixam de vê-los como possíveis inimigos. Há um senso comum entre os alunos no sentido de que eles podem trabalhar juntos, mesmo sendo de povos diferentes e inclusive com o homem da cidade e, podem buscar o bem comum e o respeito às diferenças e, isso também é cidadania.
Amostra 3: Meu povo confia em mim. Querem que eu aprenda com homem da universidade e me forme professor e volte para ajudar aldeia.

Análise: Verifica-se a existência de um sentido de família ou de pertencer a um povo com cultura e tradições e língua comum. $O$ aluno tem a esperança de voltar para sua aldeia levando novo saber e de modo semelhante ao pagé (que é o líder) e os membros da aldeia também depositam suas esperanças no jovem que sai da aldeia para estudar na universidade e pode voltar trazendo melhorias para todos. O senso comum presente é o da confiança e esperança num futuro meIhor para os povos indígenas. Observa-se também que fora da educação não há uma esperança visível uma vez que a sociedade não indígena busca a exploração econômica e pode trazer as doenças para as quais os povos indígenas nem sempre têm defesas.

Amostra 4: Eu gosto dos professores do curso. Eles gostam dos índios. Eles querem que nós estudemos e aprendamos a desenvolver trabalhos de pesquisa na aldeia.

Análise: Verifica-se a presença de diálogo e afetividade em relação aos professores da universidade mesmo eles sendo mundos diferentes. Como considera Nakata (2001) e também Antone (2003) o respeito às diferenças tem levado esses cursos ao sucesso. Observa-se também a seriedade e amor ao trabalho realizado pelos professores e isso se manifesta na confiança por parte dos alunos. Esse conjunto de coisas leva ao senso comum no sentido de que vale a pena estudar na universidade e esse fato é coerente com o aumento da procura pelos cursos relatados por professores.

Amostra 5: No começo vi que os estudantes dos outros cursos da Universidade ficavam longe de nós e isso me deixou triste. Nas aldeias todos se ajudam e aqui era diferente. No hotel não sabia como nos receber.

Análise: Nesta declaração de aluno pode-se verificar que inicialmente os alunos de outros cursos e mes- 
mo as pessoas da cidade não sabiam como lidar com o novo. Observa-se pela declaração que o aluno indígena apresentava a consciência de que estava na universidade para estudar e tendo vivido boa parte da vida numa aldeia na qual havia contato e interação entre as pessoas sente essa falta em relação aos alunos de outros cursos. Como considera Brasil (1997) a lei brasileira proíbe a discriminação e à medida que as pessoas vão conhecendo os diferentes e vão encontrando semelhanças e valores comuns vão se implementando o respeito. No entanto, os valores na sociedade ainda são diferentes daqueles existentes no ambiente universitário e há muita complexidade a ser superada. Um dos caminhos é a educação tanto na sociedade para que ocorra o respeito aos povos indígenas quanto desses para aprender a lidar uns com os outros. O senso comum leva os alunos a sentir que há diferenças e que elas precisam ser superadas com cidadania e bom senso.

Amostra 6: O curso ajuda a entender nosso povo, conservar nossa língua, costumes, cuidar da saúde, direitos, sociologia e o jeito de tratar os não índios com cidadania.

Análise: Verifica-se que o aluno tem uma noção clara das disciplinas ministradas no curso e que é necessária a cidadania que foi observada também em outros alunos como senso comum. As noções de saúde, direitos e do tratamento social com aqueles que não são membros da comunidade, pode trazer a possibilidade de entendimento entre os diferentes e a esperança de que no futuro possa existir um melhor convívio e o aumento dos povos indígenas como etnias importantes do nosso país e que precisam ser respeitados e preservados. O senso comum é no sentido de que o curso forme professores que vão contribuir com o desenvolvimento de suas aldeias e povos.

\section{CONSIDERAÇÕES FINAIS}

O presente artigo contribui para a sociedade, os professores e leitores com o saber sobre as representações sociais dos alunos de um curso superior de Licenciatura Indígena que é intercultural uma vez que há alunos de vários povos indígenas com alunos que vêm de regiões distantes, muitas vezes do meio da floresta, de aldeias afastadas dos centros urbanos e cujo proces- so seletivo inclui um componente que foi a indicação por parte do pagé e outro a entrevista além das provas objetivas. No artigo procurou-se desvelar as representações sociais associadas dos alunos indígenas de um curso de Licenciatura Indígena buscando saber deles que políticas públicas governamentais consideravam ser úteis, o que consideravam importante no curso, quais eram as perspectivas para a atuação após formados.

O trabalho mostra que os estudantes acreditam que a educação dos povos indígenas tem se tornado um diferencial que tem possibilitado discutir as dificuldades, buscar formas de minimizar/a queda da população indígena, permitindo ainda que haja a preservação das línguas, costumes, tradições, culturas e a busca por melhores condições de saúde, qualidade de vida, sabedoria e sustentabilidade para estes povos. Uma das formas eficazes e eficientes, ao que tudo leva crer é por meio dos cursos especificamente voltados para os povos indígenas.

Segundo Brasil (2016), já existem 16 cursos superiores desta modalidade em funcionamento no país. Nesses cursos recebem-se alunos de etnias e aldeias diversas e a grande maioria fala idiomas diferentes de modo que se torna um desafio, conseguir comunicar com todos e, realizar a integração procurando preservar línguas e valores de cada um e com cidadania e respeito por todos. Há alunos formados no curso que atuam como professores indígenas em suas aldeias e com isso houve um encantamento por parte dos povos indígenas que passaram a buscar essa sabedoria por meio dessa graduação.

Por meio da educação tornou-se possível a valorização da cultura, língua, tradições, atividades conjuntas e de integração entre diferentes povos, a convivência pacífica entre povos diferentes, a busca de alternativas sustentáveis, saúde, sustentabilidade e de valores importantes para os povos indígenas, de modo que já se tem minimizado tensões e, possibilitado a ocorrência da evolução e desenvolvimento conforme o interesse dos indígenas, desta forma, acredita-se que por meio do saber tem-se diminuído as mortes por suicídio e também por outras causas.

Verificou-se que havia e ainda existem interesses profundos na busca por lucros por parte do Agronegócio, das empresas Mineradoras e dos fazendeiros, posseiros e outros que querem invadir e se apossar ou de terras ou de riquezas do solo dos indígenas. Por 


\section{revista educação}

meio do poder econômico, fazendeiros ou organizações, muitas vezes, criam seus pequenos exércitos particulares contrariando a legislação. Dessa forma, criaram-se situações complexas e que precisam ser tratadas pelos Governos com a devida seriedade e rapidez na forma da lei.

O senso comum revela que os alunos do curso de Licenciatura Indígena entrevistados neste trabalho apontam no sentido da confiança dos povos indígenas em relação à educação fornecida pelas universidades, em direção ao entendimento e trabalho colaborativo entre diferentes etnias para que não haja a extinção, no respeito às diferenças e à cidadania e na esperança de um futuro melhor para os povos indígenas e as gerações
A ESPERANÇA INDÍGENA ATRAVÉS DE POLITICAS PÚBLICAS BRASILEIRAS Marcio Magera Conceição, Ricardo Shitsuka, Maria Fani Scheibel, Max Leandro de Araújo Brito

novas que poderão contar com professores bem formados e que poderão contribuir para o desenvolvimento de suas comunidades.

Nestes tempos líquidos considerados por Bauman (2007) e nos quais vivemos, para se buscar a superação em relação às complexidades torna-se interessante que se trabalhe mais do que em qualquer época, a educação da forma preconizada por Morin (2014), ou seja, pela valorização da convivência com as diferenças, o amor ao próximo, cidadania e sustentabilidade.

Sugere-se para trabalhos futuros que se estudem e se conheçam mais sobre os resultados dos cursos de Licenciatura Indígena junto às comunidades, aldeias e povos indígenas.

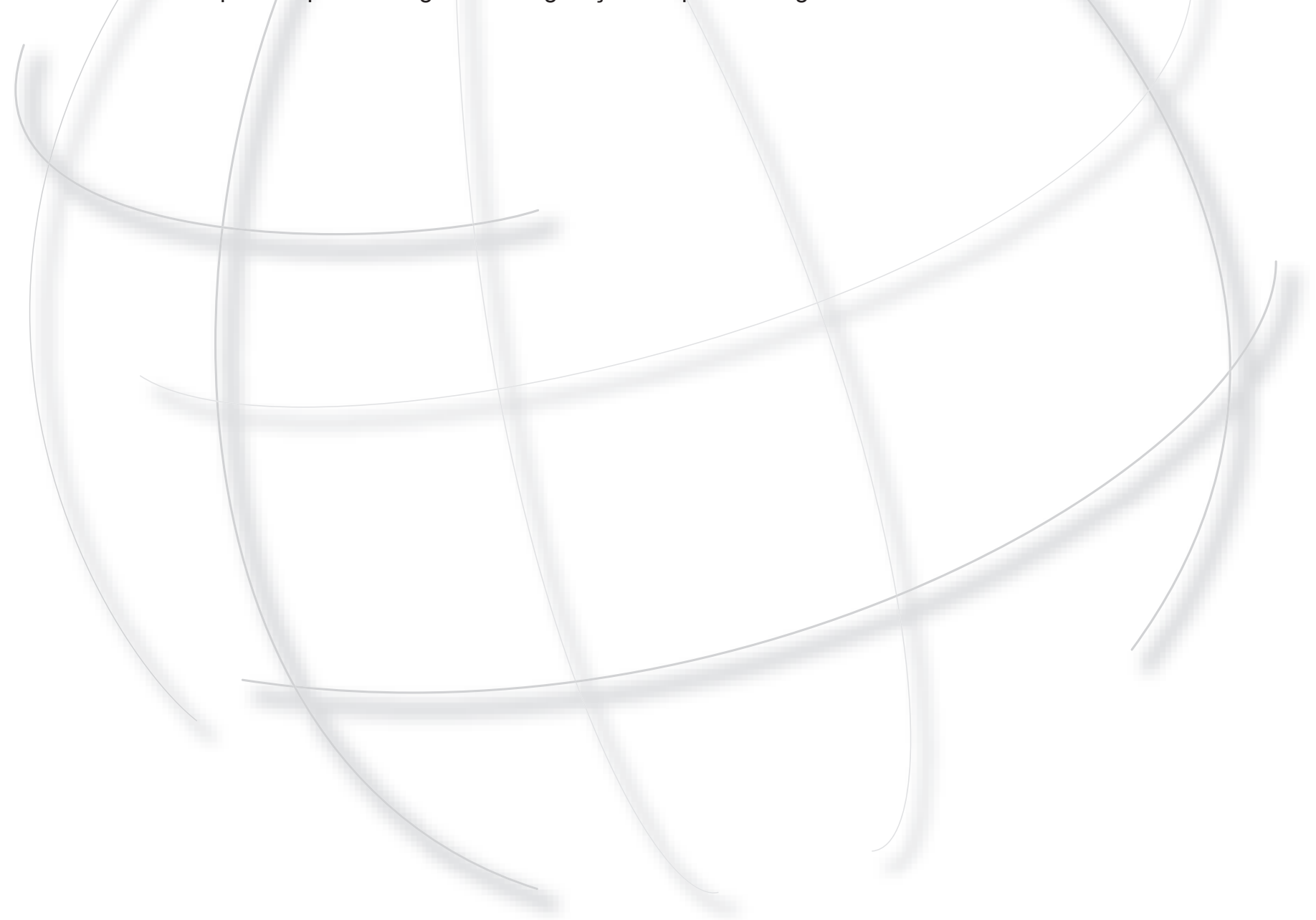




\section{REFERÊNCIAS}

ANTONE, E. Culturally framing aboriginal literacy and learning. Canadian Journal of Native Education, v. 27, n. 1, p. 7-15. 2003.

AZEVEDO, M. M. Diagnóstico da população indígena no Brasil. Cienc. Cult., São Paulo, v. 60, n. 4, p.1922, Oct. 2008. Disponível em: <http://cienciaecultura.bvs.br/scielo.php?script=sci_arttext\&pid=S0009$-67252008000400010 \&$ Ing $=e n \& n r m=i s o>$. Acesso em: 16 ago. 2019.

BAKHTIN, M. A estética da comunicação verbal. São Paulo: Martins, 2011.

BARRETO, M. P. O infanticídio indígena no Brasil sob a perspectiva do controle de convencionalidade: enfoque nos direitos humanos. Colección Victor. Salamanca: Ediciones Universidad de Salamanca, 2016.

BAUMAN, Z. Tempos líquidos. São Paulo: Cortez, 2007.

BOTEGA, N. J. Comportamento suicida: epidemiologia. Psicologia USP, v. 25, n. 3, p. 231-236. 2014. Disponível em: <http://www.scielo.br/pdf/pusp/v25n3/01036564-pusp-25-03-0231.pdf>. Acesso em: 15 ago. 2019.

BRAGA, C. F.; CAMPOS, H. F. Representações sociais, comunicação e identidade: o indígena na mídia impressa. Comunicação \& Informação, v. 16, n. 2, p. $107-$ 122, jul./dez. 2013.

BRASIL. Leis e Decretos. Lei n. 9.459 de 13 de maio de 1.997. Itera os arts. $1^{\circ}$ e 20 da Lei $n^{\circ} 7.716$, de 5 de janeiro de 1989, que define os crimes resultantes de preconceito de raça ou de cor, e acrescenta parágra-

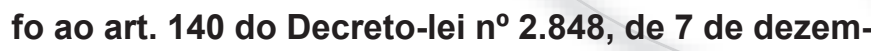
bro de 1940. Disponível em: <http://www.planalto.gov. br/ccivil_03/Leis/L9459.htm>. Acesso em: 15 ago. 2019.
BRASIL. Curso de licenciatura intercultural indígena fortalece comunidades: aulas elevam autoestima e fortalecem cultura das populações indígenas. Publicado no Portal Brasil em 20/04/2016. Disponível em: <http:// www.brasil.gov.br/educacao/2016/04/ curso-de-licenciatura-intercultural-indigena-fortalece-comunidades $>$. Acesso: 15 ago. 2019.

BRASIL. Leis e Decretos. Resolução CNE/CP n. 1 de 7 de janeiro de 2015. Institui Diretrizes Curriculares Nacionais para a Formação de Professores Indígenas em cursos de Educação Superior e de Ensino Médio e dá outras providências. Disponível em: <http://portal.mec.gov.br/index.php?option=com_ docman\&view=download\&alias $=16870$-res-cnecp-001-07012015\&category_slug=janeiro-2015pdf\&Itemid=30192> . Acesso em: 16 ago. 2019.

CIMI. Relatório violência contra os povos indígenas no Brasil: dados de 2015. Publicado pelo Conselho Indigenista Missionário - CIMi em 2015. Disponível em: <http://www.mpf.mp.br/atuacao-tematica/ccr6/documentos-e-publicacoes/mapa-da-violencia-contra-os-povos-indigenas/relatoriodados2015.pdf>. Acesso em: 15 ago. 2019.

FOLHA. O que faz o Brasil ter 190 línguas em perigo de extinção: invasão de territórios indígenas é uma das principais ameaças às línguas. Publicado no website do Jornal Folha de São Paulo em 4 de março de 2018. Disponível em: <https://www1. foIha.uol.com.br/cotidiano/2018/03/o-que-faz-o-brasil-ter-190-linguas-em-perigo-de-extincao.shtml?utm_ source =facebook\&utm_medium =social $\& u t m$ campaign=compfb $>$. Acesso em: 16 ago. 2019.

GIL, A. C. Como elaborar projetos de pesquisa. 6. ed. São Paulo: Atlas, 2017. 
IBGE. Censo 2010. Disponível em: <https://censo2010. ibge.gov.br/ >. Acesso em: 15 ago. 2019.

LUDKE, M.; ANDRE, M. E. D.A. Pesquisa em educação: abordagens qualitativas. 2. ed. São Paulo: EPU, 2013.

LYOTARD, J-F. A condição pós moderna. Lisboa: Gradiva,1979.

MATTAR, J. Metodologia cientifica na era digital. São Paulo: Saraiva, 2017.

MOONEN, F. Povos indígenas no Brasil. 2. ed. Recife: DHNET, 2008.

MORGADO, A. F. Epidemia de Suicídio entre os Guaraní-Kaiwá: Indagando suas Causas e Avançando a Hipótese do Recuo Impossível. Cadernos de Saúde Pública, RJ, v. 7, n. 4, p.585-598. 1991.

MORIN, E. Os sete saberes necessários à educação do futuro. São Paulo: Cortez, 2014.

MOSCOVICl, S. Representações sociais: investigações em psicologia social. 6. ed. Rio de Janeiro: Vozes, 2009.

NAKATA, M. Difficult dialogues in Indigenous domains. In: M. Kalantzis and B. Cope, Reconciliation, multiculturalism and identities: difficult dialogues, sensible solutions. (pp. 109-114). Melbourne. 2001.

OLIVEIRA, C. S.; LOTUFO Neto, F. Suicídio entre povos indígenas: um panorama estatístico brasileiro. Rev. Psiq. Clín., v. 30, n. 1. p. 4-10. 2003.
PÊCHEUX, M. Análise do discurso. Campinas: Pontes, 2011.

PEREIRA, M. M. Representações de suicídio indígena no Amazonas: o que desencadeia a vontade de morrer? Diversitates Int J., v. 9, n. 1, p.03-26. 2017.

PEREIRA, A. S. et al. Metodologia da pesquisa cientifica. [e-book]. Santa Maria/RS, Ed. UAB/NTE/UFSM. Disponível em: <https://repositorio.ufsm.br/bitstream/ handle/1/15824/Lic_Computacao_Metodologia-Pesquisa-Cientifica.pdf?sequence=1>. Acesso em: 15 ago. 2019.

SHITSUKA, R. et al. Xadrez e a estratégia de poder nas organizações. Rio de Janeiro: Ciência Moderna, 2004.

SILVA, P. C. D.; SHITSUKA, R.; SHITSUKA, D. M. A Imprensa brasileira e suas representações sociais: um estudo sobre a Imagem da imprensa brasileira representada nas charges. Dialogos de la Comunicación, v. 90, n. 1, p. 1-22. Disponível em: <http://dialogosfelafacs.net/ wp- content/uploads/2015/90/Dialogos90_LA_PRENSA _BRASILENA_Y_SUS_REPRESENTACIONES.pdf>. Acesso em: 16 ago. 2019.

SOUZA, M. L. P.; ORELLANA, J. D. Y. Desigualdades na mortalidade por suicídio entre indígenas e não indígenas no estado do Amazonas, Brasil. J. Bras. Psiquiatr., v. 62 , n. 4, p.245-52. 2013. 